October 2, 2006

\title{
The Welfare Costs of Expected and Unexpected Inflation
}

\author{
Miquel Faig and Zhe Li \\ University of Toronto*
}

\begin{abstract}
The monetary search model by Lagos and Wright (2005) is extended with imperfect information about nominal shocks à la Lucas (1972 and 1973). This framework is useful to estimate the welfare costs of expected and erratic inflation because it provides an avenue to identify the transactions affected by monetary shocks and how tolerant individuals are to the fluctuations of output in these transactions. We find that the welfare gain of eliminating the United States monetary business cycle observed from 1892 to 2005 is 0.01 percent of GDP while the welfare gain of reducing the observed average rate of inflation to the Friedman rule is 0.26 per cent of GDP, that is almost two orders of magnitude higher.
\end{abstract}

We are thankful to the participants of the Cleveland Feb Summer Workshop 2006 for their comments and encouragement. We are also grateful for the financial support of SSHRC of Canada. The usual disclaimer applies.

* Department of Economics, University of Toronto, 150 St. George Street, Toronto, Canada, M5S 3G7. E-mail: mfaig@chass.utoronto.ca and zhe.li@utoronto.ca. 


\section{Introduction}

Expected inflation represents an implicit tax on money balances. To avoid this tax, individuals modify their behavior thus causing a welfare cost. In the presence of nominal rigidities, unexpected and erratic inflation undermines the information transmitted through the price system causing another welfare cost. Most of the literature has studied these two costs separately. However, we discover synergies in the combination of both analyses in the Lagos-Wright (JPE 2005) framework extended with imperfect information about nominal shocks à la Lucas (JPE 1972).

The welfare cost of an erratic monetary policy depends not only on the variability it generates on real GDP (the monetary business cycle), but also on the concentration of these effects to a particular segment of the economy, and on the tolerance of individuals to the fluctuations of output in that segment. There is no reason to believe that this tolerance can be estimated from the risk premium in financial markets because individuals may be quite willing to tolerate fluctuations in the consumption of a subset of goods, but be highly intolerant to fluctuations in their total consumption, or vice versa. (One may easily tolerate wide fluctuations in restaurant meals, but be very intolerant to fluctuations in total food intake. Vice versa, one may easily tolerate wide fluctuations in the purchase of drinks, but be very intolerant to fluctuations in beer intake.)

The Lagos-Wright model provides an avenue to identify the transactions affected by monetary shocks and how tolerant individuals are to the fluctuations of output in these transactions. For unexpected monetary shocks to generate real effects, expenditures must be responsive to extra liquidity, and prices must be instrumental to allocate output. Therefore, we can narrow down the transactions affected by nominal shocks to those for which money is essential because contracts on the terms of these transactions are either impossible or impractical. Moreover, the tolerance of individuals to fluctuations on the expenditures involved in these transactions is pinned down by the elasticity of these expenditures with respect to the nominal rate of interest. Therefore, the shape of the money demand curve provides not only information about the welfare cost of expected inflation, as it has been traditionally recognized, but also it provides key information to estimate the tolerance of individuals to the monetary business cycle, and hence the welfare cost of unexpected inflation.

Our empirical analysis indicates that the welfare gain of eliminating the United States monetary business cycle observed from 1892 to 2005 is 0.01 percent of GDP while the welfare gain of reducing the observed average rate of inflation to the Friedman rule is 0.26 per cent of GDP (over one order 
of magnitude higher). This calls for a major reconsideration of what issues are most policy relevant in monetary economics.

The rest of the paper is organized as follows. Section 2 describes the model of the paper. Section 3 provides the analytical solution of the model in a special case that preferences are logarithmic and shocks are log-normally distributed. Section 4 calibrates the model to United States data. This calibration requires using preferences that are not logarithmic, so the model has to be solved numbericall. Finally, Section 5 concludes with a brief summary of the main results.

\section{The Model}

Time is discrete and the horizon is infinite. Each period consists of two subperiods to be called day and night. There is a single non-durable good. During the day, the good is traded in a centralized market with perfect information. During the night, it is traded in $N \geq 2$ decentralized markets, where personal identities are anonymous and asset holdings are private information. In the day market, everybody can produce and consume the good. At the night markets, a fraction of the population are able to produce the good and the remaining fraction get utility from their consumption. The individuals who can produce at night are called sellers, while those who then can consume are called buyers. Following Rocheteau and Wright (2005) and Lucas (1972 and 1973), both the day and night markets are competitive.

There is a continuum of buyers and sellers. Sellers are evenly distributed across all night markets, and their measure in each one of them is normalized to 1. Buyers are randomly distributed across the night markets, so the measure of buyers at market $i$ in period $t$ is a stochastic variable $n_{i t}>0$. The distributions of $n_{i t}, i=1, \ldots, N$ and $t=0,1, \ldots$ are identical across markets and time, and independent across time. Moreover, $E\left(n_{i t}\right)=1$.

Following Lagos and Wright (2005), preferences are assumed to be quasi-linear to generate a tractable distribution of money balances. The instantaneous utility of a buyer who visits night market $i$ at date $t$ is:

$$
U^{b}\left(x_{t}^{b}, y_{t}^{b}, q_{i t}^{b}\right)=v\left(x_{t}^{b}\right)-y_{t}^{b}+u\left(q_{i t}^{b}\right)
$$

where $x_{t}^{b}$ and $y_{t}^{b}$ are respectively quantities consumed and produced during the day, and $q_{i t}^{b}$ is the quantity consumed during the night. Likewise, the instantaneous utility of a seller is:

$$
U^{s}\left(x_{t}^{s}, y_{t}^{s}, q_{i t}^{s}\right)=v\left(x_{t}^{s}\right)-y_{t}^{s}-c\left(q_{i t}^{s}\right)
$$


The lifetime utilities of buyers and sellers are $E \sum_{t=0}^{\infty} \beta^{t} U^{h}\left(x_{t}^{s}, y_{t}^{s}, q_{i t}^{h}\right)$, for $h=b$ and $s$, and $\beta \in$ $(0,1)$ is the one period discount factor. The functions $v, u$, and $c$ are all continuously differentiable and increasing. The functions $v$ and $u$ are concave, while $c$ is convex. Moreover, $v(0)=u(0)=$ $c(0)=c^{\prime}(0)=0$, and $u^{\prime}(0)=\infty$. Finally, there are $x^{*}$ and $q^{*}$ such that $v^{\prime}\left(x^{*}\right)=1$ and $u^{\prime}\left(q^{*}\right)=$ $c^{\prime}\left(q^{*}\right) .^{1}$

In this environment, there is a role for a medium of exchange to facilitate trade because at night there is a lack of double coincidence of wants and all traders are anonymous. We further assume that the government has the monopoly on issuing money, which is the only counterfeit-proof note in the economy, so money is essential. Money is an intrinsically useless, perfectly divisible, and storable asset. The money supply grows at a random factor $\gamma_{t}: M_{t+1}=\gamma_{t} M_{t}$, where $M_{t}$ is the quantity of money per buyer. The distribution of $\gamma_{t}$ is independent and identically across time, and the unconditional mean of the inverse of $\gamma_{t}$ satisfies: $\beta E \gamma_{t}^{-1}<1$. The units of money are called dollars. New money is injected via a uniform lump-sum transfers to all buyers at the beginning of the night. This form of introducing money differs from Lucas's classical contributions, which assumed that transfers are proportional to the money balances held by their receipient. This difference matters little for the effect of monetary shocks on output, but it allows for a welfare cost of expected inflation, which is absent in Lucas's contributions.

The same anonymity that makes money essential prevents long-term contracts between buyers and sellers regulating the transactions taking place at night. Consequently, at night liquidity has a direct effect on buyers' demands, and spot prices are the coordinating device in the $N$ night markets. As in the second model of Rocheteau and Wright (2005), these markets are assumed to be competitive. Furthermore, following Lucas (1972 and 1973), we focus on recursive equilibria, where prices are functions of the state variables.

A full description of the state of the economy includes the distribution of money and wealth at the beginning of each subperiod, and the distribution of the allocation of buyers at night. However, quasi-linear preferences imply that consumption and the demand for money during the day are independent of wealth (see below). As a result, in the recursive equilibrium we focus on, the price of the day good for money, $P_{t}$, depends only on $M_{t}$; and the relative pricea of a night good for the day good of the same period, $p_{i t}$, depends on the vector of the realized values of the two stochastic variables $\left(\gamma_{t}, n_{i t}\right)$. As it will be proven below, $p_{i t}\left(\gamma_{t}, n_{i t}\right)$ is monotonic in both arguments, and

\footnotetext{
${ }^{1}$ If production is constrained to be non-negative, then our characterization of an equilibrium is valid as long as the choice of $y_{t}^{b}$ and $y_{t}^{s}$ is interior for all $t$. (Is $c^{\prime}\left(q^{*}\right) q^{*}<x^{*}$ sufficient?)
} 
because of recursivity and symmetry this function is the same in all periods and all night markets.

At the night of period $t$, the buyers who visit market $i$ know the quantity of money they carry, so they can infer the growth factor the money supply $\gamma_{t}$. Also, they know the price $p_{i t}$. These two pieces of information allow them to infer $n_{i t}$. In contrast, sellers ignore both $\gamma_{t}$ and $n_{i t}$, so in general $p_{i t}$ conveys information about $\gamma_{t}$ and $n_{i t}$, but does not perfectly reveal neither one of these two variables. This is the signal extraction problem emphasized by Lucas (1972 and 1973).

As is standard, in a recursive equilibrium the nominal price of day goods $P_{t}$ is proportional to the quantity money $M_{t}$, because a proportional change in these two variables leaves individual incentives and opportunities as well as market clearing conditions unaltered. However, as in Lucas classical contributions monetary shocks have real effects in the night markets because sellers when they observe a high price cannot be certain if there has been a positive monetary shock $\left(\gamma_{t}\right.$ is large) or a positive real shock ( $n_{i t}$ is large). Hence, monetary shocks affect the incentives that determine the supply of goods.

\section{Optimal Behavior}

Consider a buyer who starts day $t$ with $m_{0 t}^{b}$ dollars and faces a nominal price of goods $P_{t}$. Let $z_{0 t}^{b}$ be the real value of $m_{0 t}^{b}$, that is $z_{0 t}^{b}=m_{0 t}^{b} / P_{t}$. Consumption, $x_{t}^{b}$, production, $y_{t}^{b}$, and real money balances at the end of the day, $z_{t}^{b}$, are constrained by the following budget:

$$
x_{t}^{b}+z_{t}^{b}=y_{t}^{b}+z_{0 t}^{b}, \quad z_{t}^{b} \geq 0 .
$$

Denoting as $V_{t}^{b}$ the value function at the beginning of the night and $\Phi$ the joint distribution function of $p_{i t}$ and $\gamma_{t}$, the buyer solves the maximization program:

$$
W_{t}^{b}\left(z_{0 t}^{b}\right)=\max _{\left\{x_{t}^{b}, y_{t}^{b}, z_{t}^{b}\right\}}\left[v\left(x_{t}^{b}\right)-y_{t}^{b}+\int V_{t}^{b}\left(z_{t}^{b}, p_{i t}, \gamma_{t}\right) d \Phi\left(p_{i t}, \gamma_{t}\right)\right]
$$

subject to (3). The solution of this maximization program defines the value function $W_{t}^{b}$ at the beginning of the day.

At night the purchasing power of the buyer is limited by the money acquired during the day, $z_{t}^{b}$, plus the real value of the lump-sum transfer received from the government $\Delta_{t}$. Consequentely, the buyer solves:

$$
V_{t}^{b}\left(z_{t}^{b}, p_{i t}, \gamma_{t}\right)=\max _{q_{i t}^{b}}\left[u\left(q_{i t}^{b}\right)+\beta W_{t+1}^{b}\left(\frac{z_{t}^{b}+\Delta_{t}-p_{i t} q_{i t}^{b}}{\gamma_{t}}\right)\right]
$$


subject to:

$$
p_{i t} q_{i t}^{b} \leq z_{t}^{b}+\Delta_{t}
$$

In this expression, it has been used that in a recursive equilibrium $P_{t+1}=\gamma_{t} P_{t}$, and $\gamma_{t}$ is known by the buyer at the night of $t$.

The analogous relations for a seller are the following. The maximization problem for the day is identical to that of a buyer:

$$
W_{t}^{s}\left(z_{0 t}^{s}\right)=\max _{\left\{x_{t}^{s}, y_{t}^{s}, z_{t}^{s}\right\}}\left[v\left(x_{t}^{s}\right)-y_{t}^{s}+\int V_{t}^{s}\left(z_{t}^{s}, p_{i t}, \gamma_{t}\right) d \Phi\left(p_{i t}, \gamma_{t}\right)\right]
$$

subject to the budget constraint

$$
x_{t}^{s}+z_{t}^{s}=y_{t}^{s}+z_{0 t}^{s}, \quad z_{t}^{s} \geq 0 .
$$

In contrast, the maximization program for the night has two important differences:

$$
V_{t}^{s}\left(z_{t}^{s}, p_{i t}\right)=\max _{q_{i t}^{s}}-c\left(q_{i t}^{s}\right)+\beta \int W_{t+1}^{s}\left(\frac{z_{t}^{s}+p_{i t} q_{i t}^{s}}{\gamma_{t}}\right) d F\left(\gamma_{t} \mid p_{i t}\right)
$$

First, there is no liquidity constraint binding the optimal supply of goods. Second, the seller does not know $\gamma_{t}$, but it uses $p_{i t}$, the relation $p_{i t}\left(\gamma_{t}, n_{i t}\right)$, and the joint distribution $\Phi\left(p_{i t}, \gamma_{t}\right)$ to calculate the conditional distribution $F\left(\gamma_{t} \mid p_{i t}\right)$.

As in Lagos and Wright (2005), the quasi-linear preferences in (4) and (7) imply that day consumption for buyers and sellers is the efficient quantity that satisfies $v^{\prime}\left(x^{*}\right)=1, x_{t}^{b}=x_{t}^{s}=x^{*}$. Moreover, the day value functions are affine with unit marginal values of real money balances and constant terms which are independent of time: $W_{t}^{b}\left(z_{t}^{b}\right)=w^{b}+z_{t}^{b}$ and $W_{t}^{s}\left(z_{t}^{s}\right)=w^{s}+z_{t}^{s}$ for all $t$. Combining these functional forms with (5) and (9), the optimal choices at night solve the following programs:

$$
\begin{gathered}
\max _{q_{i t}^{b}}\left[u\left(q_{i t}^{b}\right)-\frac{\beta p_{i t} q_{i t}^{b}}{\gamma_{t}}\right] \text { subject to } p_{i t} q_{i t}^{b} \leq z_{t}^{b}+\Delta_{t} . \\
\max _{q_{i t}^{s}}\left[-c\left(q_{i t}^{s}\right)+\beta \int \frac{p_{i t} q_{i t}^{s}}{\gamma_{t}} d F\left(\gamma_{t} \mid p_{i t}\right)\right] .
\end{gathered}
$$

The net demand functions that solve (10) and (11) are denoted respectively as $\tilde{q}^{b}\left(z_{t}^{b}, \Delta_{t}, \gamma_{t}, p_{i t}\right)$ and $\tilde{q}^{s}\left(p_{i t}\right)$.

To characterize the optimal demand for money, it is convenient to use the day budget (3) and the night Bellman equation (5) to eliminate $y^{b}$ and $V_{t}^{b}$ from the day optimization program (4). With this transformation, the first order condition that characterizes $z_{t}^{b}$ is

$$
\int\left\{\beta \gamma_{t}^{-1}+\varrho_{t}\right\} d \Phi\left(p_{i t}, \gamma_{t}\right)=1
$$


where $\varrho_{t}$ is the Lagrange multiplier associated with (6). This condition can be conveniently transformed using the first order condition for the optimal choice of $q_{t}^{b}$ in (10) to obtain:

$$
\int\left\{p_{i t}^{-1} u^{\prime}\left[\tilde{q}^{b}\left(z_{t}^{b}, \gamma_{t}, p_{i t}, \Delta_{t}\right)\right]\right\} d \Phi\left(p_{i t}, \gamma_{t}\right)=1
$$

That is, buyers equate the expected marginal benefit of $z_{t}^{b}$ at night with the marginal cost of its acquision during the day. Regardless of being cash contrained or not, the marginal value of money at night is the marginal utility of the goods one can purchase with an extra dollar. So, the expected marginal benefit of $z_{t}^{b}$ in utils is the integral in the LHS of (12). To acquire an extra real unit of money, the buyer must supply an extra unit of $y_{t}^{b}$, which costs one util, as stated in the RHS of (12).

As a vehicle for saving from period $t$ to period $t+1$, money's return factor is $E\left(\gamma_{t+1}^{-1}\right)$. Since the utility discount factor is $\beta$ and by assumption $\beta E\left(\gamma_{t+1}^{-1}\right)<1$, no individual should carry money balances that with certainty will not be spent during the night. Therefore, the seller's optimal demand for money is zero: $z_{t}^{s}=0$ for all $t$. Also, buyers should face a binding liquidity constraint (6) in at least one of the markets they can potentially visit at night, so in the margin their money balances are not only an instrument for saving, but also an instrument to facilitate their transactions.

A recursive equilibrium is a set of real numbers $z^{b}$ and $\Delta$, which respectively describe the buyer's money demand $z_{t}^{b}$ and the monetary transfer $\Delta_{t}$ for all $t$, and a set of real functions $p\left(\gamma, n_{i}\right), q^{b}\left(\gamma, n_{i}\right)$, and $q^{s}\left(\gamma, n_{i}\right)$, which respectively map the realized values the shocks $\gamma_{t}$ and $n_{i}$ onto the prices $p_{i t}$ and the quantities $q_{i t}^{b}$ and $q_{i t}^{s}$ traded at night markets for all $i$ and $t$, that satisfy the following: ${ }^{2}$

\section{Optimal behavior:}

(a) $q^{b}\left(\gamma, n_{i}\right)=\tilde{q}^{b}\left[z^{b}, \Delta, \gamma, p\left(\gamma, n_{i}\right)\right]$.

(b) $q^{s}\left(\gamma, n_{i}\right)=\tilde{q}^{s}\left[p\left(\gamma, n_{i}\right)\right]$.

(c) $E\left\{\left[p\left(\gamma, n_{i}\right)\right]^{-1} u^{\prime}\left[q^{b}\left(\gamma, n_{i}\right)\right]\right\}=1$.

\section{Market clearing:}

$$
n_{i} q^{b}\left(\gamma, n_{i}\right)=q^{s}\left(\gamma, n_{i}\right)
$$

\footnotetext{
${ }^{2}$ To complete the description of the equilibrium allocation, during the day all individuals consume $x^{*}$, and produce whatever quantities $y^{b}$ or $y^{s}$ needed for the budget constraints (3) and (8) to hold. Market clearing, ensured by Walra's Law, implies that aggregate day production is $2 x^{*}$.
} 


\section{Government budget:}

$$
\Delta=z^{b}(\gamma-1)
$$

4. Rational expectations: $F\left(\gamma \mid p_{i}\right)$ in (11) is the distribution of $\gamma$ conditional $p_{i}=p\left(\gamma, n_{i}\right)$.

In what follows, time subscripts are dropped when this does not create ambiguity.

[Existence and monotonicity properties to be added here]

\section{Efficient Allocation}

The efficient allocation solves:

$$
\max _{\left\{q_{i}^{b}, q_{i}^{s}\right\}} \int\left[n_{i} u\left(q_{i}^{b}\right)-c\left(q_{i}^{s}\right)\right] d i \quad \text { subject to } n_{i} q_{i}^{b}=q_{i}^{s} .
$$

The solution to this program is:

$$
u^{\prime}\left(q_{i}^{b}\right)=c^{\prime}\left(q_{i}^{s}\right), \text { for all } i
$$

Define the Frieman Rule, as the monetary policy in which $\sigma_{\gamma}^{2}=0$ and $\gamma \downarrow \beta$. Under the Friedman Rule, the rate of return on money is the subjective discount rate. Since day value functions are affine, individuals are willing to hold money even if it were not the medium of exchange at night. Consequently, the liquidity constraint (6) cannot be strictly binding and the solution to the optimization programs (10) and (11) are respectively $u^{\prime}\left(q_{i}^{b}\right)=p_{i}$ and $c^{\prime}\left(q_{i}^{s}\right)=p_{i}$. Therefore, under the Friedman Rule, condition (16) holds.

\section{Special Case: Lucas (1973)}

One of the difficulties of solving for a recursive equilibrium is that, in contrast to Lucas (1972 and 1973), buyers do not always spend all the money balances they carry. That is, conditions in the market a buyer visits may be such that the solution to the optimization problem (10) is interior. This complication can be easily dealt with numerical methods, but in general it prevents an explicit solution to the model. An exception to this general rule is when buyers have logarithmic preferences for the night good, in which case, as shown in the next paragraph, buyers spend all their money in whatever night market they visit. Moreover, if the sellers's disutility of production and the distribution function of shocks are chosen appropriately, the explicit solution one can then 
obtain is similar to the solution of the reduced form model by Lucas (1973), which has become a fixture in undergraduate macroeconomics textbooks.

Let $u\left(q_{i}^{b}\right)=\ln \left(q_{i}^{b}\right)$. The first order condition that result from applying the Kuhn-Tucker Theorem to the optimization program (10) is $q_{i}^{b} p_{i}=\gamma \min \left\{z^{b}, \beta^{-1}\right\}$ for all $i$. If $z^{b}<\beta^{-1}$, the liquidity constraint (6) is not binding and the optimum is interior. Otherwise, (6) is binding and buyers exhaust their money balances. In any case, buyers' expenditures are the same in all markets they visit. Intuitively, because a high $p_{i}$ in market $i$ means that the good for sale is relatively expensive, buyers purchase a low $q_{i}^{b}$; with logarithmic preferences, the demand elasticity of $q_{i}^{b}$ with respect to $p_{i}$ is minus one, so the high $p_{i}$ exactly compensates for the low $q_{i}^{b}$ to make the expenditure $q_{i}^{b} p_{i}$ independent from $p_{i}$. Furthermore, the optimum cannot be interior because then the buyer would be carrying money balances in excess of the maximum quantity ever purchased, which as seen above is suboptimal. ${ }^{3}$ Consequently, with logarithmic preferences the buyers demand for goods at night obeys:

$$
q_{i}^{b}=\frac{\gamma z^{b}}{p_{i}}
$$

Combining (12) with (17), the buyers demand for money during the day is:

$$
z^{b}=E\left(\gamma^{-1}\right)
$$

To obtain an explicit solution similar to Lucas (1973), we further assume that $c\left(q^{s}\right)=\left(q^{s}\right)^{1+\alpha} /(1+$ $\alpha)$ and the stochastic shocks are log-normal: $\ln \gamma \sim N\left(\mu_{\gamma}, \sigma_{\gamma}^{2}\right)$ and $\ln n_{i} \sim N\left(\mu_{n}, \sigma_{n}^{2}\right)$. With this functional forms, the optimal demand for money during the day, and the optimal supply of goods at night implied by (11) are:

$$
\begin{gathered}
z^{b}=\exp \left(-\mu_{\gamma}+\frac{\sigma_{\gamma}^{2}}{2}\right), \text { and } \\
q_{i}^{s}=\left[\beta p_{i} E\left(\gamma^{-1} \mid p_{i}\right)\right]^{\frac{1}{\alpha}}
\end{gathered}
$$

Therefore, substitution of (17) and (20) into the market clearing condition: (13) yields

$$
n_{i} \gamma=\frac{p_{i}^{1+\frac{1}{\alpha}}\left[\beta E\left(\gamma^{-1} \mid p_{i}\right)\right]^{\frac{1}{\alpha}}}{z^{b}} .
$$

The RHS of (21) is a function $p_{i}$, while the LHS is the product of the realized values of the two stochastic variables unobserved by the sellers. Therefore, observing $p_{i}$ in a recursive equilibrium carries the same information as observing $n_{i} \gamma$, so $F\left(\gamma \mid p_{i}\right)=F\left(\gamma \mid \omega_{i}\right)$, where $\omega_{i}=n_{i} \gamma$. That is,

\footnotetext{
${ }^{3}$ Notice that if the optimum were interior, (12) would simplify to $E\left(\gamma^{-1}\right)=\beta^{-1}$, which contradicts the assumption $E\left(\gamma^{-1}\right)<\beta^{-1}$.
} 
finding $F\left(\gamma \mid p_{i}\right)$ turns out to be equivalent to the standard signal extraction problem of knowing the unconditional distributions of two log-normally distributed random variables $n_{i}$ and $\gamma$ and finding the distribution of one of them conditional on observing the realized value of their product. As explained in Lucas (1973), the distribution of $\gamma$ conditional on $\omega_{i}$ is log-normal and characterized by the following two moments::

$$
\begin{aligned}
E\left(\ln \gamma \mid \omega_{i}\right) & =\theta \mu_{\gamma}+(1-\theta)\left(\ln \omega_{i}-\mu_{n}\right), \text { and } \\
\operatorname{Var}\left(\ln \gamma \mid \omega_{i}\right) & =\theta \sigma_{\gamma}^{2}, \text { where } \\
\theta & =\frac{\sigma_{n}^{2}}{\sigma_{n}^{2}+\sigma_{\gamma}^{2}} .
\end{aligned}
$$

In words, the conditional mean of $\ln \gamma$ is a weighted average between two pieces of information: the unconditional mean $\mu_{\gamma}$ and $\log$ of the observed product corrected to also have unconditional mean $\mu_{\gamma}$. If monetary shocks are small or real shocks are large $\left(\sigma_{\gamma}^{2} \rightarrow 0\right.$ or $\left.\sigma_{\gamma}^{2} \rightarrow \infty\right)$, then $\theta \rightarrow 0$ and the unconditional mean $\mu_{\gamma}$ carries most of the weight in the average. In contrast, if real shocks are small or monetary shocks are large $\left(\sigma_{n}^{2} \rightarrow 0\right.$ or $\left.\sigma_{\gamma}^{2} \rightarrow \infty\right)$, then $\theta \rightarrow 1$, so current observations of the $p_{i}$ and so $\omega_{i}$ carry most of the weight in forming the conditional mean $E\left(\ln \gamma \mid \omega_{i}\right)$. The conditional variance of $\ln \gamma$ is increasing in both $\sigma_{n}^{2}$ and $\sigma_{\gamma}^{2}$.

Subsituting (22) into (21) yields the equilibrium price at the night markets:

$$
p_{i}=A^{-1}\left(z^{b}\right)^{\frac{\alpha-\theta}{1+\alpha}}\left(\gamma n_{i}\right)^{(1-\lambda)}
$$

The values of $z^{b}$ and $\theta$ are in (19) and (22), and the values of remaining constants are $\lambda=\theta /(1+\alpha)$, and $A=\left\{\beta \exp \left[(1-\theta) \mu_{n}\right]\right\}^{\frac{1}{1+\alpha}}$. Since $\theta \in[0,1]$ and $\alpha>0, \lambda$ must belong to the interval $(0,1)$. Therefore, $p_{i}$ is monotonically increasing in both $\gamma$ and $n_{i}$. Substituting (23) into (17) yields the equilibrium quantities demanded at the night markets:

$$
q_{i}^{b}=A\left(z^{b}\right)^{\lambda+\frac{1}{1+\alpha}} \gamma^{\lambda} n_{i}^{-(1-\lambda)}
$$

Finally, substituting (24) into the market clearing condition (13) yields:

$$
q_{i}^{s}=A\left(z^{b}\right)^{\lambda+\frac{1}{1+\alpha}}\left(\gamma n_{i}\right)^{\lambda}
$$

As advanced by Lucas (1973), sellers supply a large quantity of output in response to a large realization of the monetary shock $\gamma$. Given the information structure adopted, this is a rational response. The monetary shock increases prices at the night markets. Sellers do not know if the high prices they observe are due to a large realization of $\gamma$ or a high realization of $n_{i}$. If they knew, they 
would realize that the real return on their effort, which is the goods they can purchase the next day for one good sold at night $\left(p_{i} / \gamma\right)$, actually falls with $\gamma$ as implied by $(23)$ because $\lambda \in(0,1)$. Sellers use whatever information they have to their best advantage, and they infer that on average a high price correlates with a high return on their effort, so they respond to monetary shocks by supplying more output. The size of this response depends on the distributions of real and monetary shocks.

If monetary shocks are rare and small relative to real shocks $\sigma_{\gamma}^{2} / \sigma_{n}^{2} \rightarrow 0$, then $\theta=0$ and the elasticity of $q_{i}^{s}$ with respect $\gamma$ is large: $\lambda=1 /(1+\alpha)$. At the other extreme, if the money supply is erratic relative to real shocks $\sigma_{\gamma}^{2} / \sigma_{n}^{2} \rightarrow \infty$, then $\theta=1$ and sellers do not respond to monetary shocks $\lambda=0$. In general, $\theta$ falls and the elasticity $\lambda$ increases with $\sigma_{\gamma}^{2} / \sigma_{n}^{2}$. So, suppliers repond most strongly to monetary shocks when these are rare and small.

Since the day market is not affected by monetary shocks and all night markets face the same $\gamma$, both aggregate output and aggregate inflation are correlated with $\gamma$. Therefore, as emphasized by Lucas (1973), this model generates a short-run upward sloping Phillips curve. However, if monetary authorities were to increase the average rate of inflation by increasing $\mu_{\gamma}$, aggregate output would actually fall as it can be seen in the following equations:

$$
E q_{i}^{s}=A\left(E n_{i}^{\lambda}\right) \exp \left\{\frac{1}{1+\alpha}\left[-\mu_{\gamma}+\left(1+\theta+\frac{\theta^{2}}{1+\alpha}\right) \frac{\sigma_{\gamma}^{2}}{2}\right]\right\}
$$

which results from combining (24) with (19), the assumed log-normal distribution for $\gamma$, and the definition of $\lambda$ below (23). With higher expected inflation, buyers carry less money balances, so output at night falls. This effect of expected inflation on output is not present in Lucas's contributions because, as well known, with proportional transfers perfectly anticipated inflation has no effect on the demand for money.

\section{Estimation of the Model}

The special case studied in the previous section has the double interest of having an explicit solution and this being similar to the classical contribution by Lucas (1973). However, with logarithmic preferences the demand for money turns out to be too inelastic to fit United States historical data on nominal interest rates and the velocity of M1. For this reason, this section presents and estimates a version of the model in which the utility of consumption at night has the isoelastic form $u\left(q_{i}^{b}\right)=\left(q_{i}^{b}\right)^{1-\eta} /(1-\eta)$. The utility of consumption during the day is assumed logarithmic: $v(x)=B \log (x)$, since our results have little to do with this function form. 
As suggested by Lagos and Wright (2005), even though day markets are complete, one can assume the existence of bonds, which because of counterfeiting problems, cannot be traded at night. The Euler equation that relates day consumption $t$ and $t+1$ of an individual that uses a risk-free bond earning nominal interest $i$ is: $v^{\prime}\left(x_{t}\right)=\beta v^{\prime}\left(x_{t+1}\right)(1+i) E\left(\gamma_{t}^{-1}\right)$. Since in equilibrium $x_{t}=x^{*}$, the equilibrium nominal interest rate must be: $i=\left[\beta E\left(\gamma_{t}^{-1}\right)\right]^{-1}-1$. Using this expression, the real demand for money (18) can be written as follows: $z^{b}=[\beta(1+i)]^{-1}$. Consequently, the absolute value of the interest semi-elasticity of the demand for money is $(1+i)^{-1}<1$. Using historical United States time series on M1 and nominal interest rates, the absolute value of this semi-elasticity is around 5, so the model with logarithmic utility for consuming at night generates a demand for money, which is too inelastic with respect to the nominal interest rate to be consistent with United States data.

The source of the interest elasticity of the demand for money in the present model is the elasticity of the demand for night goods with respect to the overall cost of their purchase, which includes the opportunity cost of carrying money. Consequently, the parameter $\eta$, which controls the demand elasticity of $q_{i}^{b}$, indirectly determines the elasticity of the demand for money. If $\eta$ is less than one, then demands for both $q_{i}^{b}$ and money are more elastic than with logarithm preferences, so one may sucessfully fit the model to United States data. Unfortunately for tractability purposes, if the elasticity of $q_{i}^{b}$ with respect to $p_{i}$ is above one, buyers do not wish to spend all their money balances in markets with a sufficiently high $p_{i}$, so unused or precautionary money balances are a typical equilibrium outcome. This precautionay balances are held to take good shopping opportunities that arise when buyers visit a market with low prices, and they add an additional source of elasticity to the money demand. That is, as the opportunity cost of holding money increases buyers sacrificy this good trading opportunities to economize on money balances. ${ }^{4}$

If the cash constraint (6) is not binding, the first order condition for optimality of program (10) is

$$
\left(q_{i}^{b}\right)^{-\eta}=\frac{\beta p_{i}}{\gamma}
$$

with implies that expenditure is $q_{i}^{b} p_{i}=(\gamma / \beta)^{1 / \eta} p_{i}^{1-\frac{1}{\eta}}$. Therefore, the application of Kuhn-Tucker theorem, to take into account constraint (6), yields the folling demand function:

$$
q_{i}^{b}=\frac{1}{p_{i}} \min \left\{\left(\frac{\gamma}{\beta}\right)^{\frac{1}{\eta}} p_{i}^{1-\frac{1}{\eta}}, z^{b}\right\} .
$$

\footnotetext{
${ }^{4}$ See Faig and Jerez (2006) for a monetary search model with precautionary balances due to preference shocks.
} 
With this demand function, the demand for money that result from (12) does not have an explicit solution. Consequently, we use numerical methods to solve the model, and to calibrate its parameter values.

Using historial annual data for the United States from 1892 to 2005 as reference, the parameters of the models are calibrated to match the following list of moments:

- Average continuously compounded annual rate inflation (GDP deflator): 4.14 percent.

- Standard deviation of the innovation of log of M1*: 0.0465 .

- Average annual velocity (GDP/M1*): $4.87\left(\mathrm{M}^{*}\right.$ is the M1 in circulation inside the United States).

- Interest semi-elasticity of detrended velocity: 4.52 .

- Standard deviation of the monetary business cycle (projection of the innovation of log of GDP on to the innovation of $\log$ of $\mathrm{M} 1 *)$ : 0.0193 .

In addition to this list of moments, we pick the length of a period to be one year, and calibrate the model so the risk-free real interest rate is 3 percent, and there is the same number of buyers and sellers in aggregate. Finally, we restrict the elasticity of the marginal cost of production, $\alpha$, to be 0.01 . This is a value very low to be close to the constant returns to scale assumed by Lagos and Wright (2005), but it still generates an upward sloping supply curve, which is needed for prices to partly reveal demand conditions.

The calibrated values of the parameters are the following:

- $\beta=e^{-0.03}$,

- $\mu_{\gamma}=0.0414$

- $\sigma_{\gamma}=0.0465$,

- $B=2.8123$,

- $\eta=0.1784$,

- $\sigma_{n}=0.8926$, and

- $\mu_{n}=\sigma_{n}^{2} / 2$. 
The risk-free real interest rate adjusted for the length of the model period determines the value of the discount factor $\beta$. To allow for economic growth, which is abstracted from the model, the average rate of growth of the money supply is calibrated using the average rate of inflation. The standard deviation of monetary shocks is taken to be the standard deviation of the innovation of the logarithm of $\mathrm{M1}^{*}$ (M1 in circulation inside the United States). The remaining parameters are calibrated so the model matches the observed average velocity of circulation of money, interest semi-elasticity of velocity, and amplitude of the monetary business cycle. The measure of velocity is GDP over M1*. The interest semi-elasticity of velocity is calculated regressing the logarithm of velocity on the short-term commercial paper rate and a cubic polynomial of time. This time trend is necessary to take into account that velocity in the early 21 st century is four times its value in the early 20 th century while nominal interest rates are similar. Finally, the amplitude of the monetary business cycle is measured by the standard deviation of the innovations of the log of GDP. To take into account the existence of aggregate real shocks abstracted from our model, the innovation of log of GDP in the United States is projected onto the innovations of the log of M1*. This procedure assumes no reverse causation between output and money. If reverse causation actually took place, we would be exagerating the welfare cost of erratic monetary policy, which would only reinforce our conclusion that these costs are small. On the other hand, we are abstracting for long-term effects of monetary shocks, which biases our estimate in the opposite direction. However, at the annual frequency, we do not expect that this bias is a major concern.

Once calibrated, we use the model to evaluate the welfare cost of the United States suboptimal monetary policy during the sample period, measured as the equivalent variation of income as a percentage of GDP. That is, we calculate how much residents of the United States should have been willing to pay to have faced the optimal Friedman rule instead of the prevalent monetary policy, and we express this payment as a percentage of GDP. We find this welfare cost to be 0.26 percent of GDP.

Our model also allows us to calculate how much of this welfare cost is due to the monetary business cycle generated by an erratic monetary policy, and how much it is due to a positive opportunity cost of holding money. We find that eliminating the monetary business cycle contributes very little to the welfare gain of implementing the Friedman rule. The welfare gain of reducing $\sigma_{\gamma}$ to zero and adjusting $\mu_{\gamma}$ to keep the nominal interest unchanged is equivalent to 0.01 percent of GDP. $^{5}$ Therefore, eliminating the monetary business cycle contributes 3.8 percent $(0.01 / 0.26)$ to

\footnotetext{
${ }^{5}$ With the adjustment of $\mu_{\gamma}$, the nominal interest increases slightly, so the welfare gain is even smaller: 0.003
} 
the overall welfare gain of implementing the Friedman rule, while the elimination of the opportunity cost of holding money contributes the remaining 96.2 percent.

\section{Conclusions}

Lucas non-neutrality theory can be succesfully incorporated in the framework of Lagos and Wright (2005) model, where simultaneously money is essential and individuals optimize. In general, the solution of the model is more complicated than in Lucas's (1972 and 1973) classical contributions because, depending on market conditions, money holders do not spent all the money they carry. However, an exception to this general rule occurs with logarithmic utility for goods purchased with money. In this special case, buyers always spend all the money they carry, and the model can be explicit solved to obtain a similar reduced form similar to that of Lucas (1973).

The model so developed is useful to estimate the welfare costs of expected and unexpected inflation. In the framework of the Lagos and Wright (2005) model the sector of the economy where money is essential is also the sector directly affected by monetary shocks. Moreover, the elasticity of the demand for money is informative about the tolerance of individuals to the business cycle induced by an erratic monetary policy. Using United States annual time series of output, prices, interest rates, and money balances from 1892 to 2005, the welfare cost of the monetary business

cycle is calculated to be equivalent to 0.01 percent of GDP; while the welfare cost of the inflation tax due to positive nominal interest rates is equivalent to 0.26 percent of GDP.

percent of GDP. 


\section{References}

\section{References}

[1] Faig, Miquel and Belén Jerez (2006), "Precautionary Balances and the Velocity of the Circulation of Money," Journal of Money, Credit, and Banking, forthcoming.

[2] Katzman, Brett, John Kennan, and Neil Wallace (2003), "Output and the Price Level Effects of Monetary Uncertainty in a Matching Model," Journal of Economic Theory, 108, 217-255.

[3] Lagos, Ricardo, and Randall Wright (2005), "A Unified Framework for Monetary Theory and Policy Analysis," Journal of Political Economy, 113 (3), 463-484.

[4] Lucas, Robert (1972), "Expectations and the Neutrality of Money," Journal of Economic Theory, 4, 103-124.

[5] Lucas, Robert (1973), "Some International Evidence on Output-Inflation Tradeoffs," American Economic Review, 63, 326-334.

[6] Rocheteau, Guillaume and Randy Wright (2005), "Money in Search Equilibrium, in Competitive Equilibrium, and in Competitive Search Equilibrium," Econometrica, 73, 175-202.

[7] Wallace, Neil (1997), "Short-Run and Long-Run Effects of Changes in Money in a RandomMatching Model," Journal of Political Economy, 105 (6), 1293-1307. 